\title{
The effect of salts and haematite on carboxymethyl cellulose-bentonite and partially hydrolyzed polyacrylamide-bentonite muds for an effective drilling in shale formations
}

\author{
M. Kuma' •B. M. Das² $\cdot$ P. Talukdar ${ }^{3}$
}

Received: 13 December 2018 / Accepted: 25 June 2019 / Published online: 1 July 2019

(c) The Author(s) 2019

\begin{abstract}
A common issue encountered by drilling engineers during drilling operation in oil and gas industries is that simple waterbased muds are not suitable for deeper depth and certain clay-swelling formations. Another option as to increasing the density of the drilling mud which brings about an increase in filtration loss, additives may be added to improve the fluid properties. This paper aims on determining the effectiveness of common salts, sodium chloride $(\mathrm{NaCl})$ and potassium chloride $(\mathrm{KCl})$, and haematite on the rheological properties of optimized carboxymethyl cellulose (CMC)-bentonite and partially hydrolyzed polyacrylamide (PHPA)-bentonite muds. Both CMC and PHPA polymer act as fluid loss-reducing agents and viscosifiers for normal bentonite water-based mud. The mud is further enhanced to counter certain swelling formations such as shale through the addition of $\mathrm{NaCl}$ and $\mathrm{KCl}$. These salts inhibit the shale formation from swelling through its ions by entering the lattice of the drilling mud or formation instead of the water ions. Haematite, on the other hand, basically functions to increase mud density and acts as a substitute for barite. The effect of haematite on drilling fluid was studied because it gives higher degree of rheological parameters and increases density as compared to barite. So, an optimized concentration of additives was determined for both CMC-bentonite and PHPA-bentonite mud systems, respectively. Three grams of $\mathrm{KCl}$ and $3 \mathrm{~g}$ haematite were used for $\mathrm{CMC}$-bentonite mud, while $3 \mathrm{~g} \mathrm{KCl}$ and $1 \mathrm{~g}$ haematite were added into PHPA-bentonite mud. Both these muds have shown swelling reduction as compared to those without the use of additives. Moreover, they exhibited Herschel-Bulkley fluid behaviour according to the power law model where their ' $n$ ' value was less than 1 , while their yield points were more than zero. Since shale sloughing is a major problem faced during drilling operation, it leads to major complications in drilling. So, finally, both the formulated drilling fluids are tested to analyse their effect in shale formations by static immersion test. The shale rock was collected from Champhai District of Mizoram. Both the formulated muds exhibited great results as swelling in shale rock was reduced for both muds and optimum rheological values were maintained.
\end{abstract}

Keywords CMC $\cdot$ PHPA $\cdot$ Plastic viscosity $\cdot$ Filtrate loss $\cdot$ Mud cake thickness $\cdot$ Shale inhibition

\section{Abbreviations}

CMC Carboxymethyl cellulose salt

PHPA Partially hydrolyzed polyacrylamide

B. M. Das

borkha2014@dibru.ac.in

1 Universiti Teknologi Petronas, Persiaran UTP, 32610 Seri Iskandar, Perak, Malaysia

2 Department of Petroleum Technology, Dibrugarh University, Rajabheta, Dibrugarh, Assam 786004, India

3 Department of Petroleum Engineering, DUIET, Dibrugarh University, Rajabheta, Dibrugarh, Assam 786004, India
$\mathrm{NaCl}$ Sodium chloride salt

$\mathrm{KCl}$ Potassium chloride salt

\section{Introduction}

Drilling operations always required the assistance of drilling fluids. They are a viscous fluid mixture that is used carry rock cuttings to the surface and also to lubricate and cool the drill bit. They maintain the hydrostatic pressure of the well and prevent formation damage that may occur. If the ability of the drilling fluid is compromised, disastrous outcomes will occur and the cost of repairing 
the damage will pose a serious negative impact on the oil company conducting the operation. That is the reason why general drilling fluids alone cannot be effective in all types of formation and drilling conditions. (Talukdar and Gogoi 2015) Various chemicals such as salts, polymer and haematite may be used as additives to help with property enhancements on the mud cake thickness, filtrate loss and rheological properties. These additives all have their own unique composition and functions such as being viscosifiers, weighting agents, emulsifiers, fluid loss control agents and many more. (Awele 2014) For example, both carboxymethyl cellulose (CMC) salt and PHPA polymer act as great viscosifiers and fluid loss reducing agents on drilling muds. (Iscan and Kok 2007) CMC is a cellulose derivative obtained by chemically modifying natural cellulose. It has the molecular structure of:

$\mathrm{CMC}$ is one of the best water-soluble polymers with so many advantages that other natural or synthetic glues do not have. (Limanowski 2014) PHPA, partially hydrolyzed polyacrylamide, on the other hand, is a polymer made up of basic repeating monomer units which are made up of hydrogen, carbon, nitrogen and oxygen. It has a high molecular weight and structure shown below (Figs. 1,2):

It can highly absorb on exposed clay particles to form bridges. So, as the degree of hydrolysis increases, bridging also increases, resulting in an increase in viscosity. PHPA polymer acts better as a viscosifier, but CMC performs better to reduce filtrate loss due to its smaller molecular size. (Borthakur et al. 1997) However, the purpose of this study is to find the effectiveness of $\mathrm{NaCl}, \mathrm{KCl}$ and haematite in enhancing fluid properties of optimized CMC and PHPA drilling fluids.

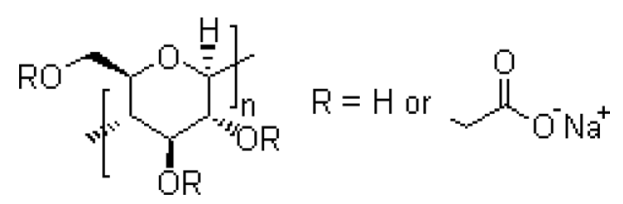

Fig. 1 Molecular structure of carboxymethyl cellulose salt. Adapted from carboxymethyl cellulose sodium (CMC)-oil drilling (https:// www.irochemical.com/product/Mud-Drilling/CMC.htm)

\section{Experimental analysis}

\section{Materials and equipments employed}

The materials and equipments which are employed for the experimental analysis are mentioned in Table 1.

\section{Methods employed}

\section{Mud formulation}

Thousand millilitres of distilled water is mixed with a stirrer with varying concentrations of bentonite powder, CMC salt, PHPA polymer, $\mathrm{NaCl}$ salt, $\mathrm{KCl}$ salt and haematite depending on their usage in the particular phase. The mud is then mixed portion by portion in a mixer cup using the Hamilton Beach Commercial Stand Mixer for 5-10 min.

\section{Determination of density and rheological properties}

\section{Density and specific gravity}

A mud balance was used by filling cup side with selected mud sample and adjusted weight on the other side until the bubble is in between the 2 indicator lines. The reading was obtained on the scale of the mud balance.

Table 1 Materials and equipment used

\begin{tabular}{lll}
\hline No. & Name & Classification \\
\hline 1 & Hamilton beach commercial stand mixer & Equipment \\
2 & Mud balance & Equipment \\
3 & Marsh funnel & Equipment \\
4 & Grace M3600 Fann G viscometer & Equipment \\
5 & Low-pressure low-temperature (LPLT) filter & Equipment \\
& press & \\
6 & Bentonite powder (sodium ions) & Material \\
7 & Carboxymethyl cellulose salt (CMC) & Material \\
8 & Partially hydrolyzed polyacrylamide (PHPA) & Material \\
9 & Sodium chloride (NaCl) & Material \\
10 & Potassium chloride (KCl) & Material \\
11 & Iron(III) oxide (haematite) & Material \\
\hline
\end{tabular}

Fig. 2 Chemical structure of partially hydrolyzed polyacrylamide polymer. Adapted from figures-partially hydrolyzed polyacrylamide (PHPA) polymer (Sharma 2016)
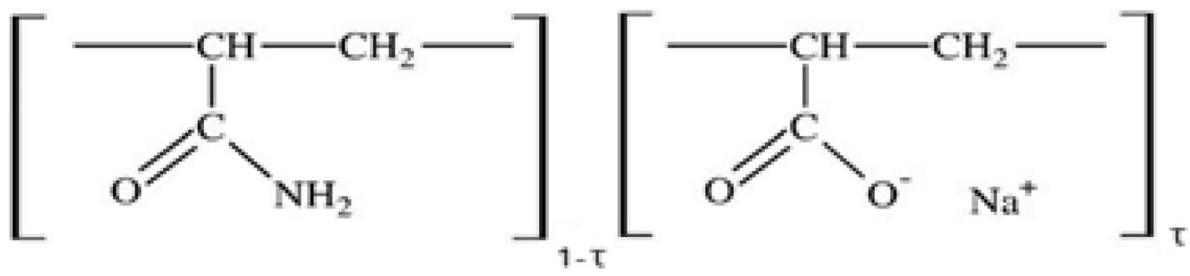


\section{Apparent viscosity-qualitative}

Nine hundred and fifty $\mathrm{ml}$ of drilling mud was placed into Marsh funnel, and the time taken for drilling mud to flow out of the Marsh funnel was recorded using a stopwatch. Effective viscosity was obtained by calculating Density * $[t-25]$ while apparent viscosity was obtained through $-0.018 t^{2}+1.6175 t-$ Determination of Density and Rheological 32.168 or Density * $[t-28]$ where $t$ is time taken for mud to flow out of Marsh funnel (Almahdawi et al. 2014).

\section{Viscometer results}

A certain amount of mud was poured into viscometer cup and hooked up into Grace M3600 Fann G Viscometer. Time taken for rotation (s), temperature (Fahrenheit) and rate of rotation (RPM) were set. Following that, shear stress and viscosity values for different RPM settings of 600 RPM, 300 RPM, 3 RPM (after $10 \mathrm{~s}$ of rest) and 3 RPM (After 10 min of rest) were taken (Lam and Jefferis 2014). From those values, the following calculations in Table 2 were made:

\section{Filtration properties determination}

Portion of mud was poured into the low-pressure low-temperature (LPLT) filter press, and it was sealed tightly with clamp to prevent leakage at the top. The pressure hook was tightened to make sure the initial pressure was 0 psi. Following that, weight column was raised to initiate filtrate loss due to the pressure exerted by its weight. Furthermore, the volume obtained from filtrate loss specifically after 7 and 30 min was noted. The pressure clamp and filter press clamp were then released, and mud cake within the apparatus was measured for its thickness using a Vernier calliper.

\section{Performance analysis of drilling mud}

The basic bentonite muds were added with varying amounts of CMC and PHPA to determine the optimum reference quantity. Both additives increased the rheological properties and reduced the filtration properties of the mud with increasing concentration. In this work, from various experimental analyses, $3.5 \mathrm{~g}$ of CMC and $3.5 \mathrm{~g}$ of PHPA were both found acceptable amounts to create optimum reference CMC-bentonite and PHPA-bentonite muds, respectively. CMC-bentonite and PHPA-bentonite drilling muds were then added with varying amounts of $\mathrm{NaCl}, \mathrm{KCl}$ and haematite on their own. Their effect on the mud with increasing concentration was observed and recorded while the best combination of these additives to be mixed into the CMC-bentonite and PHPA-bentonite mud, respectively, was determined. And so, CMC and PHPA optimum drilling muds were formulated with their respective combination of additives to investigate the difference in properties, determine the appropriate rheological model and analyse their performance ability.

The static immersion test was conducted with the final two drilling muds. Initially, four similar shale rocks from Champhai District of Mizoram were left in an oven for at least $2 \mathrm{~h}$ at $67^{\circ} \mathrm{C}$. Each one of them was then dropped into non-optimized (without additives) and optimized (with additives) CMC-bentonite and PHPA-bentonite drilling muds and left them to be for a day. After that, their weight was measured before and after immersion to see whether any swelling or expansion occurred. Finally, the rocks were dried again in the oven for at least $2 \mathrm{~h}$ before measuring their dry weight again. The data are then plotted and compared between the non-optimized and optimized CMC-bentonite and PHPA-bentonite drilling muds. The formula for swelling and spalling is as follows:

Table 2 Calculations based on viscometer readings

Plastic Viscosity $(\mathrm{cp})=[$ Shear Stress $(600 \mathrm{RPM})-$ Shear Stress $(300 \mathrm{RPM})] / 5.11$

Apparent Viscosity $(\mathrm{cp})=[$ Shear Stress $(600 \mathrm{RPM}) / 2] / 5.11$

Yield Point $\left(l b f / 100 f t^{2}\right)=[$ Shear Stress $(300$ RPM $) / 5.11]-$ Plastic Viscosity

Gel strength $($ Initial $)=$ Set 600 RPM for $10 \mathrm{~s}$

$=$ Wait for $10 \mathrm{~s}$

$=$ Set 3 RPM and take shear stress reading

$=$ Convert shear stress $\left(\right.$ dynes $\left./ \mathrm{cm}^{2}\right)$ to dial reading $\left(l b f / 100 f t^{2}\right)$ by dividing 5.11

Gel strength $($ After $10 \mathrm{~min})=$ Once again, Set 600 RPM for $10 \mathrm{~s}$

$=$ Wait for $10 \mathrm{~min}$

$=$ Set 3 RPM agian and take shear stress value

$=$ Convert shear stress to dial reading $\left(l b f / 100 f t^{2}\right)$ by dividing 5.11 


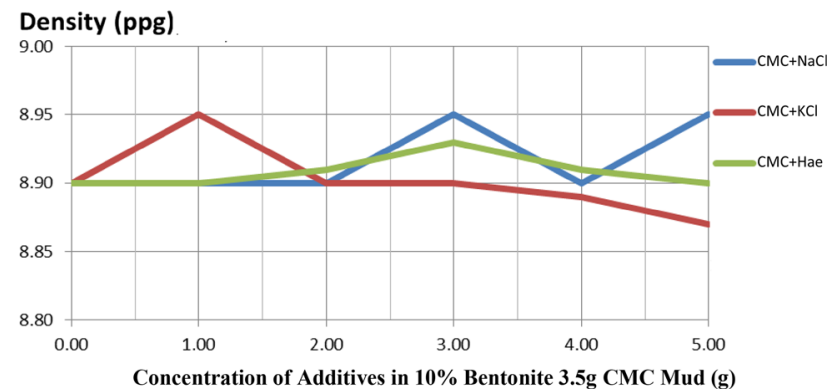

Fig. 3 Effect of $\mathrm{NaCl}, \mathrm{KCl}$ and haematite on density of $\mathrm{CMC}$-bentonite mud

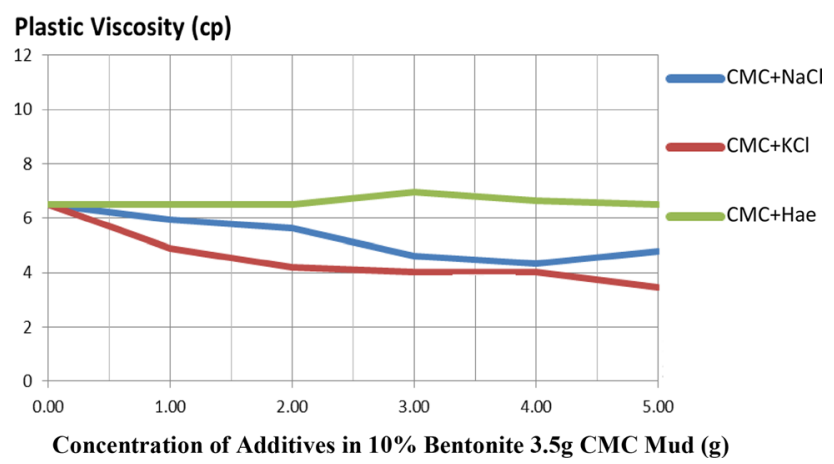

Fig. 4 Effect of $\mathrm{NaCl}, \mathrm{KCl}$ and haematite on plastic viscosity of CMC-bentonite mud

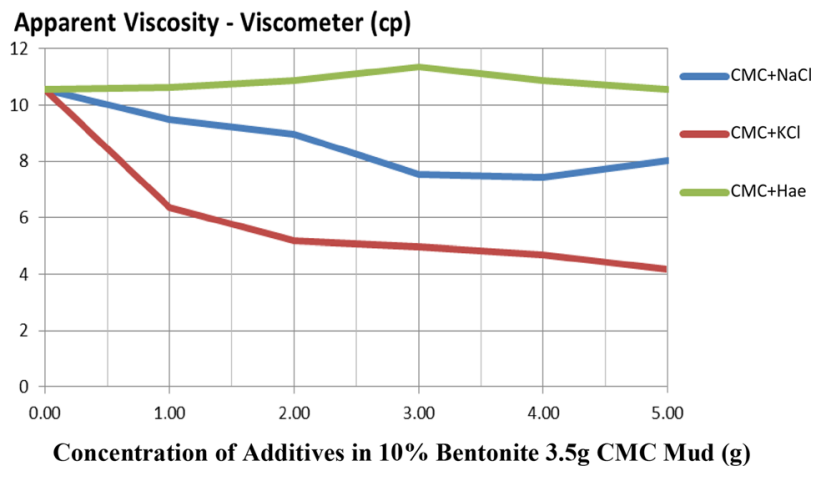

Fig. 5 Effect of $\mathrm{NaCl}, \mathrm{KCl}$ and haematite on apparent viscosity of CMC-bentonite mud

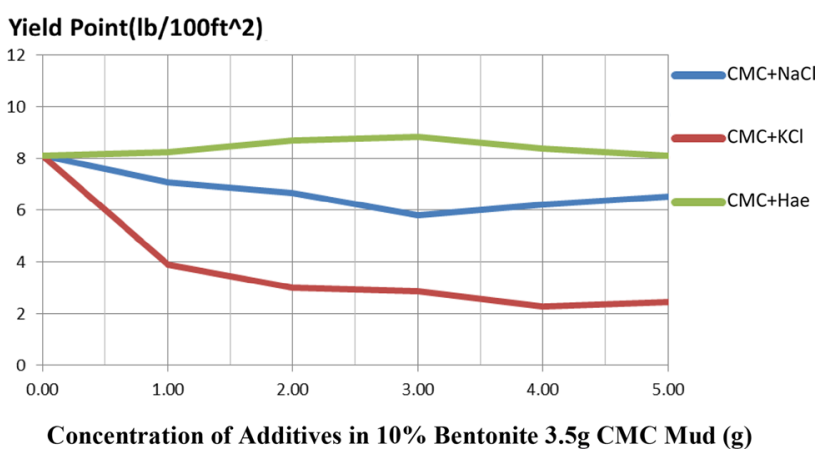

Fig. 6 Effect of $\mathrm{NaCl}, \mathrm{KCl}$ and haematite on yield point of $\mathrm{CMC}-$ bentonite mud

Swelling $(\%)=\frac{\text { Weight of Wet Rock }(\mathrm{g})-\text { Weight of dried rock after immersion }(\mathrm{g})}{\text { Weight of dried rock after immersion }(\mathrm{g})}$

Spalling $(\%)=\frac{\text { Initial dry weight of rock }(\mathrm{g})-\text { Weight of dried rock after immersion }(\mathrm{g})}{\text { Weight of dried rock after immersion }(\mathrm{g})}$

\section{Results and discussion}

\section{CMC-bentonite fluid mixed with additives}

\section{Density and rheological properties}

It has been observed from Figs. 3, 4, 5, 6, 7 and 8 that the addition of all the additives rarely affects the density and apparent viscosity of the reference $\mathrm{CMC}-$ bentonite mud.

However, when tested for their effect on the rheological properties, a certain trend could be seen. Higher addition of $\mathrm{KCl}$ and $\mathrm{NaCl}$ was reducing all the properties of the mud. Haematite, on the other hand, does slightly increase the reference mud's properties but cannot be said to be very effective. Another observation that was made is that $\mathrm{KCl}$ affects and reduces the rheological properties more than $\mathrm{NaCl}$.

\section{Filtration properties}

In addition to the rheological properties, the filtration properties have also increased with higher concentration of $\mathrm{NaCl}$ and $\mathrm{KCl}$ in the reference mud as it is seen in Figs. 9 and 10.

$\mathrm{KCl}$ is seemingly increasing the filtrate loss and mud cake thickness more than $\mathrm{NaCl}$. A reduction in the rheological and filtration properties is not desired in a drilling mud; however, the reason behind this is what makes their application much more desirable which is due to swelling reduction.

\section{Variation of properties with time}

The data above in Figs. 11, 12 and 13 are most important when investigating the effects of these salts on drilling mud. 


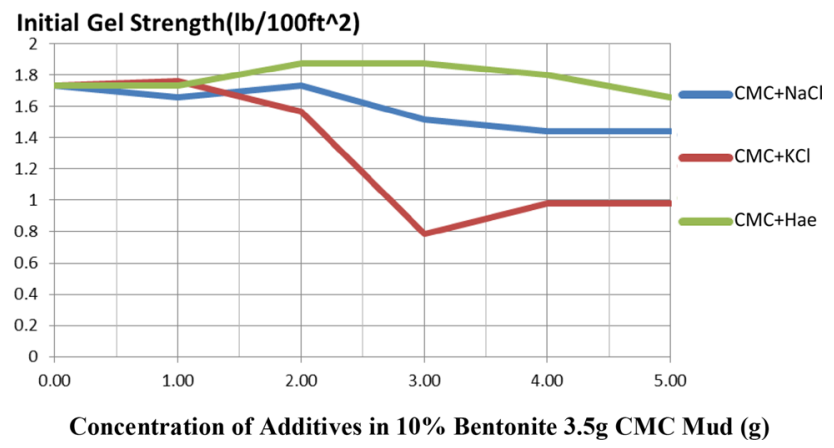

Fig. 7 Effect of $\mathrm{NaCl}, \mathrm{KCl}$ and haematite on gel strength (initial) of CMC-bentonite mud

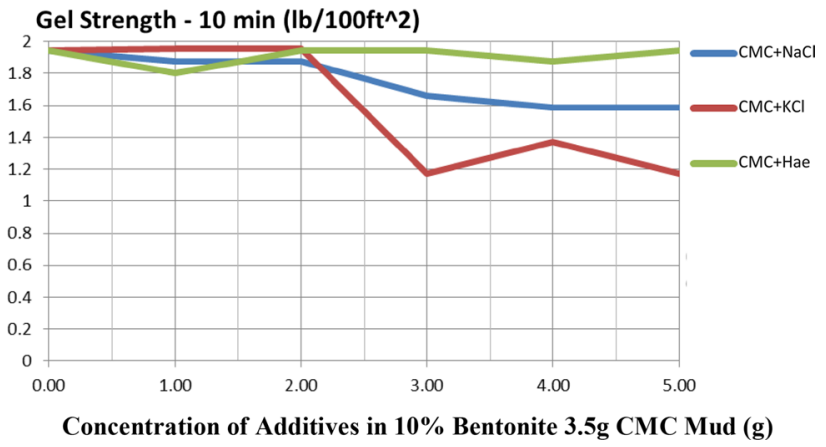

Fig. 8 Effect of $\mathrm{NaCl}, \mathrm{KCl}$ and haematite on gel strength (after $10 \mathrm{~min}$ ) of CMC-bentonite mud

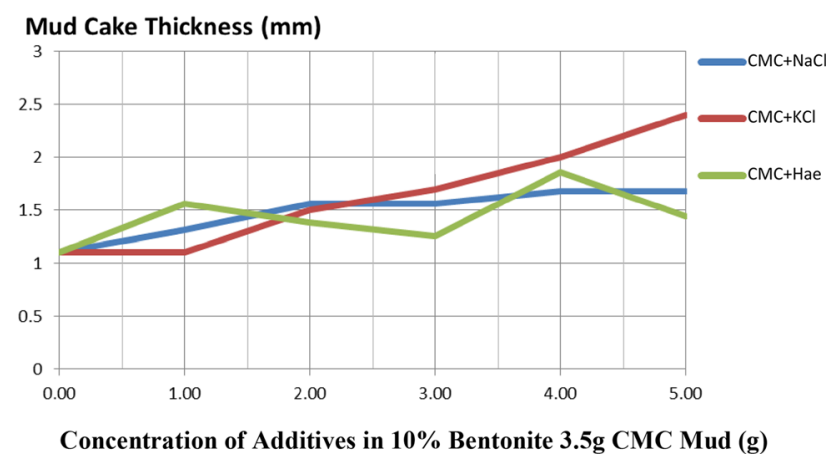

Fig. 9 Effect of $\mathrm{NaCl}, \mathrm{KCl}$ and haematite on mud cake thickness of CMC-bentonite mud

As depicted in Fig. 11, the plastic viscosity of the fluid does increase if left for few days due to swelling process. However, the swelling is inhibited with the increasing addition of $\mathrm{NaCl}$. The difference in plastic viscosity values when the mud was first formulated and after it was left for a few days have been decreasing with the addition of $\mathrm{NaCl}$ and $\mathrm{KCl}$ as highlighted by the circled area in the graphs. For

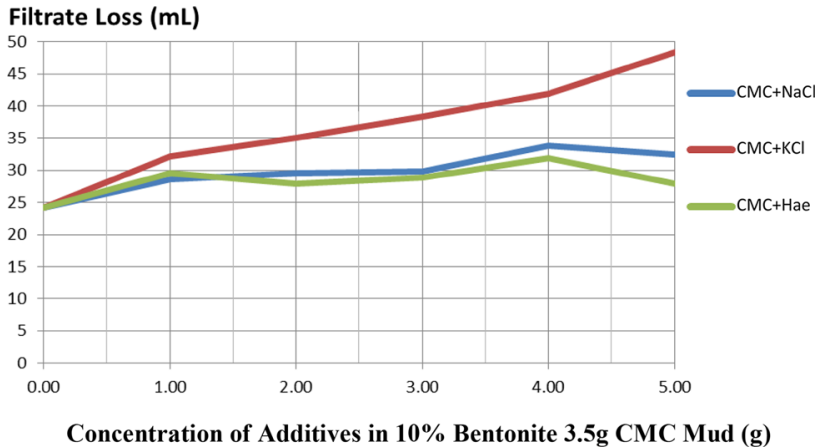

Fig. 10 Effect of $\mathrm{NaCl}, \mathrm{KCl}$ and haematite on filtrate loss of $\mathrm{CMC}-$ bentonite mud

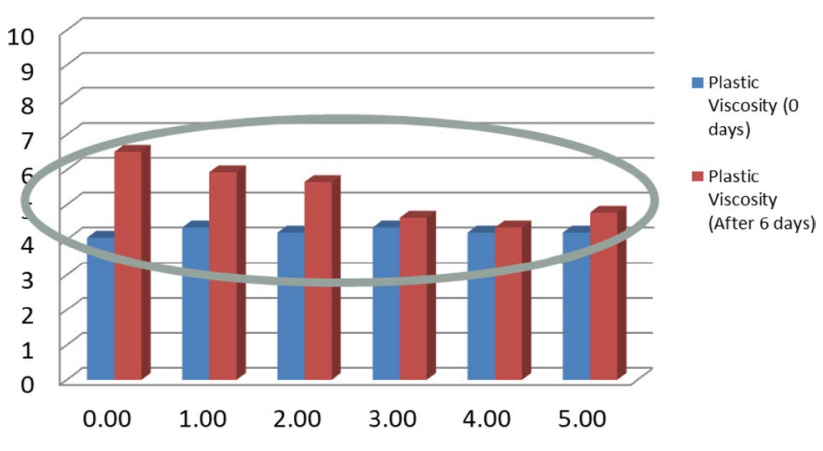

Concentration of NaCL in 10\% Bentonite 3.5g CMC Mud (g)

Fig. 11 Effect of $\mathrm{NaCl}$ on plastic viscosity of CMC-bentonite mud in accordance with time

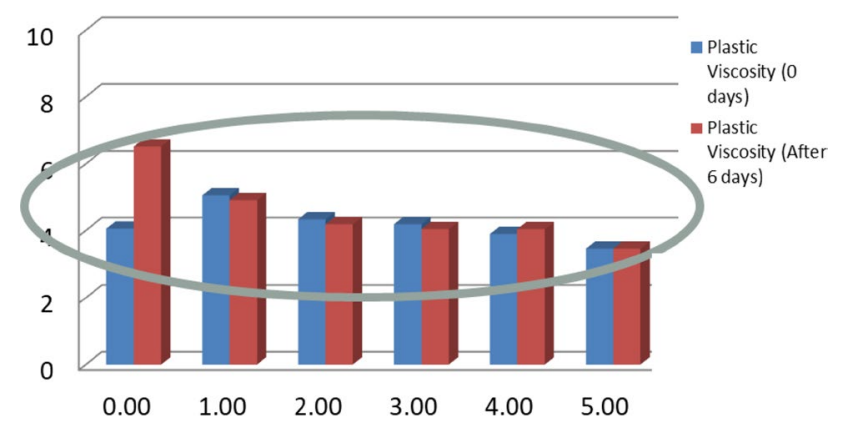

Concentration of KCL in 10\% Bentonite 3.5g CMC Mud (g)

Fig. 12 Effect of $\mathrm{KCl}$ on plastic viscosity of $\mathrm{CMC}-$ bentonite mud in accordance with time

increasing amount of $\mathrm{NaCl}$, the plastic viscosity is slowly becoming unaffected by the swelling process. In the $\mathrm{KCl}$ data, it has been found that with little addition itself the swelling process has decreased drastically. This means that in theory these salts are very much effective in preventing 


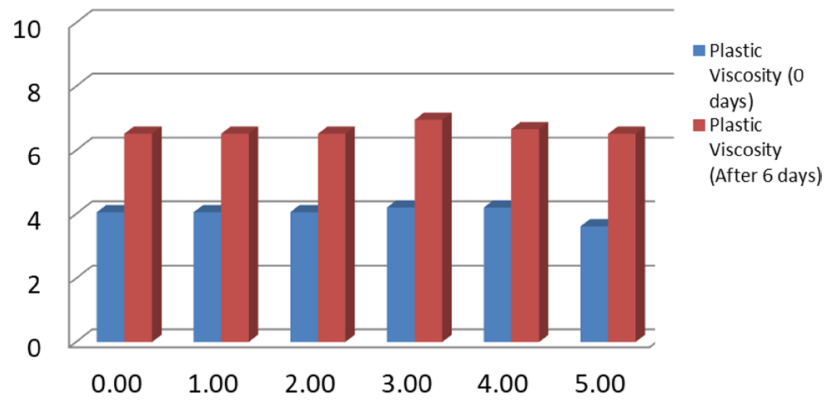

Concentration of Haematite in 10\% Bentonite 3.5g CMC Mud (g)

Fig. 13 Effect of haematite on plastic viscosity of CMC-bentonite mud in accordance with time

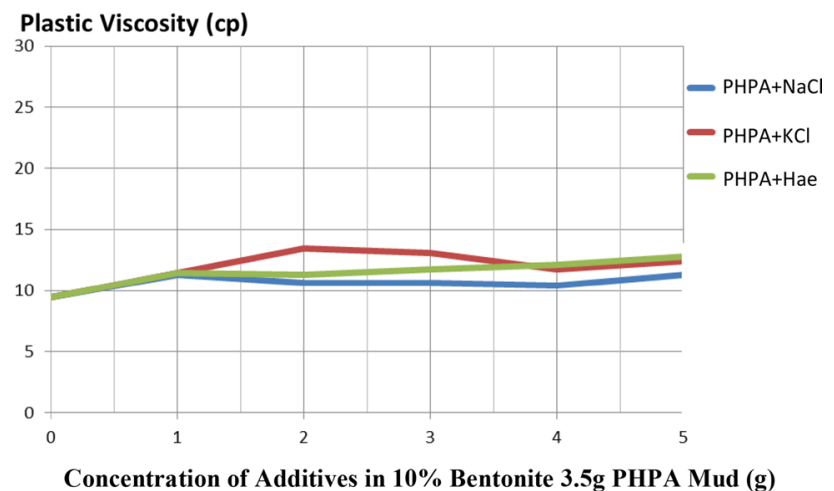

Fig. 14 Effect of $\mathrm{NaCl}, \mathrm{KCl}$ and haematite on plastic viscosity of PHPA-bentonite mud

the occurrence of swelling when drilling in formations that swell such as shale. The potassium and sodium ions actually move into the lattice of the drilling mud or formation instead of water ions. And as for haematite data, it is seen that the swelling occurs as normal because haematite does not affect the swelling process and just slightly increases the rheological properties (Kanna et al. 2017). More concentration of haematite is to be used if proper findings about its effect can be concluded.

\section{PHPA-bentonite fluid mixed with additives}

\section{Rheological properties}

The effect of addition of salts and haematite on the rheological properties of PHPA-bentonite mud is shown in Figs. 14, 15, 16, 17 and 18.

The interpretation of the effect on rheological properties in fact can be divided into two. For instance, plastic viscosity and apparent viscosity stay same or slightly increases with higher concentration of additives. This is most probably due to the higher solid contents in the mud meaning that

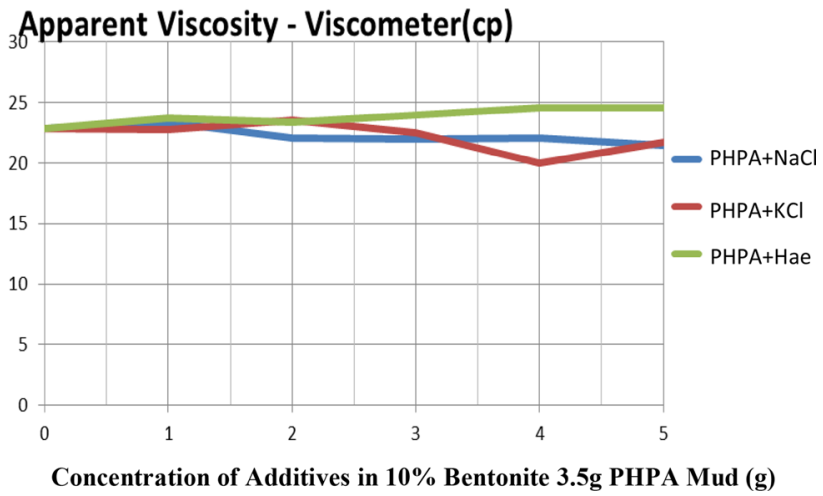

Fig. 15 Effect of $\mathrm{NaCl}, \mathrm{KCl}$ and haematite on apparent viscosity of PHPA-bentonite mud

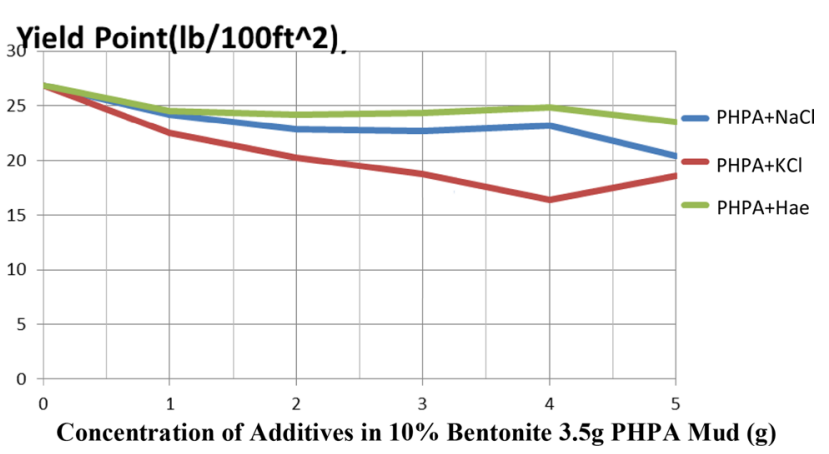

Fig. 16 Effect of $\mathrm{NaCl}, \mathrm{KCl}$ and haematite on yield point of PHPAbentonite mud

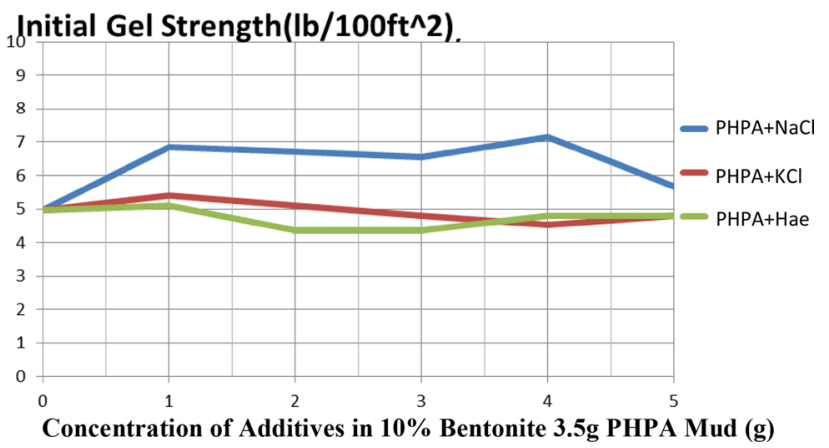

Fig. 17 Effect of $\mathrm{NaCl}, \mathrm{KCl}$ and haematite on gel strength (initial) of PHPA-bentonite mud

the additives are not completely mixed with the mud due to the gel form. However, the yield point and gel strength of the mud decrease with more $\mathrm{NaCl}$ and $\mathrm{KCl}$ addition which shows swelling reduction. Haematite does not have much effect, so it must be tested at higher concentration with the mud samples. 


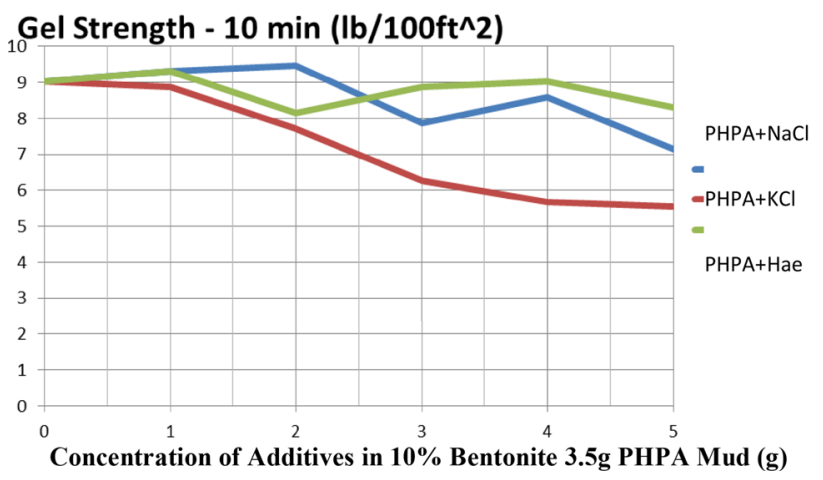

Fig. 18 Effect of $\mathrm{NaCl}, \mathrm{KCl}$ and haematite on gel strength (after $10 \mathrm{~min}$ ) of PHPA-bentonite mud

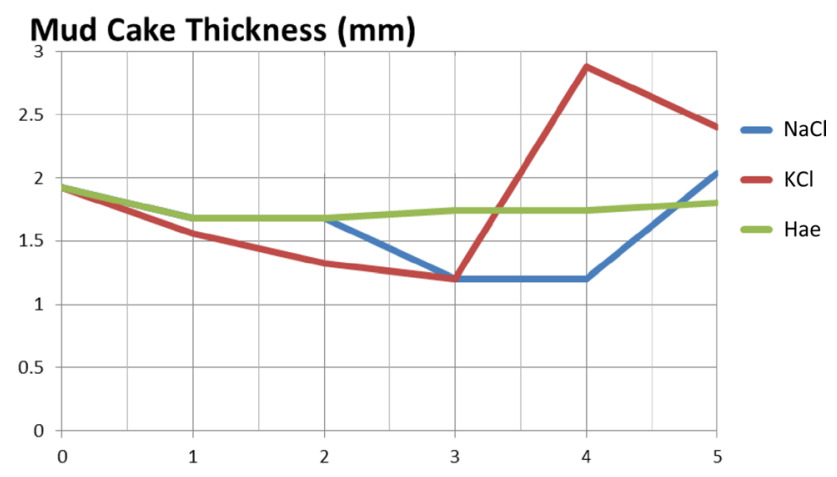

Concentration of Additives in 10\% Bentonite 3.5g PHPA Mud (g)

Fig. 19 Effect of $\mathrm{NaCl}, \mathrm{KCl}$ and haematite on mud cake thickness of PHPA-bentonite mud

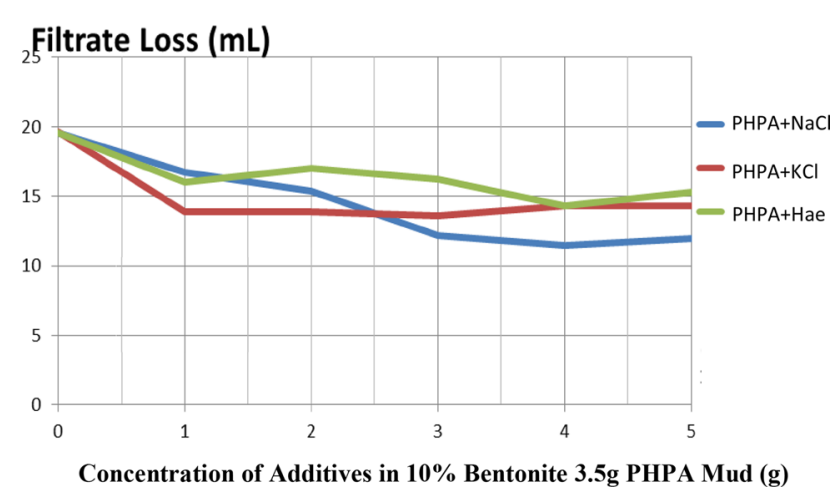

Fig. 20 Effect of $\mathrm{NaCl}, \mathrm{KCl}$ and haematite on filtrate loss of PHPAbentonite mud

\section{Filtration properties}

Furthermore, the filtration properties seemed to decrease a bit with the addition of salts and haematite, but there is a slight increase in mud cake thickness when $4 \mathrm{~g}$ of $\mathrm{KCl}$ is added to the PHPA reference mud (Figs. 19, 20).

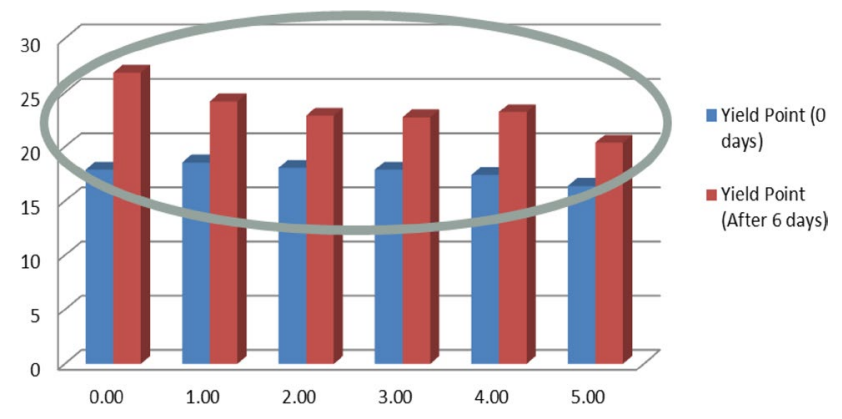

Concentration of NaCL in 10\% Bentonite 3.5g PHPA Mud (g)

Fig. 21 Effect of $\mathrm{NaCl}$ on yield point of PHPA-bentonite mud in accordance with time

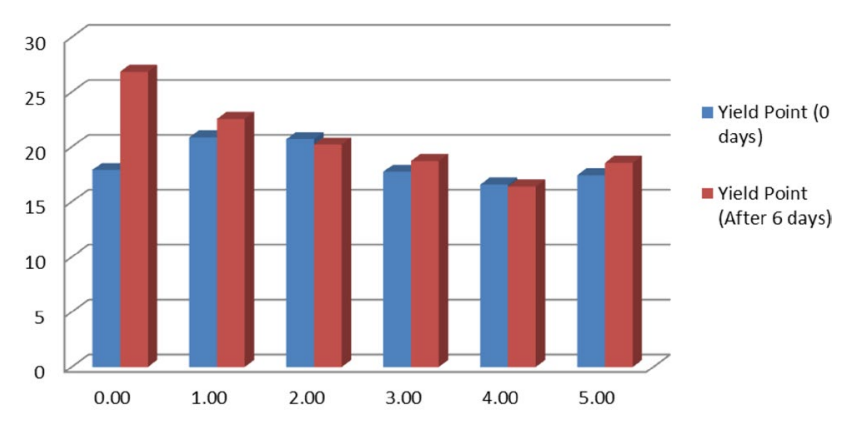

Concentration of KCL in 10\% Bentonite 3.5g PHPA Mud (g)

Fig. 22 Effect of $\mathrm{KCl}$ on yield point of PHPA-bentonite mud in accordance with time

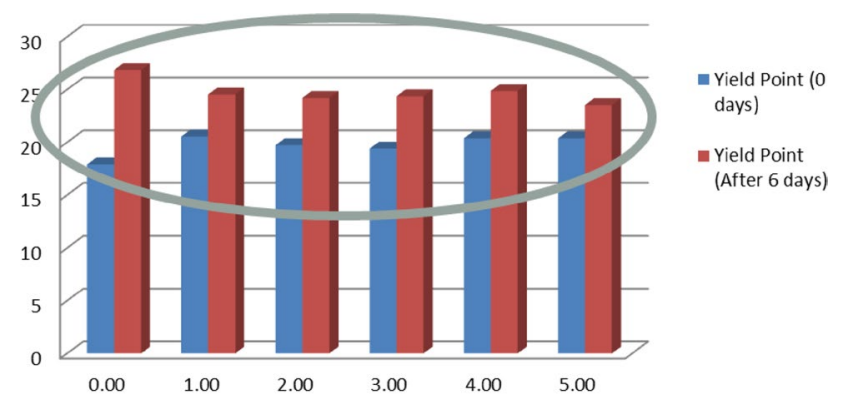

Concentration of Haematite in 10\% Bentonite 3.5g PHPA Mud (g)

Fig. 23 Effect of haematite on yield point of PHPA-bentonite mud in accordance with time

It can be interpreted that higher concentration of these additives needs to be added and tested with this reference mud to obtain more concrete results. The gel-like structure of PHPA muds may be rendering small concentrations of these additives ineffective (Figs. 21, 22, 23, 24). 


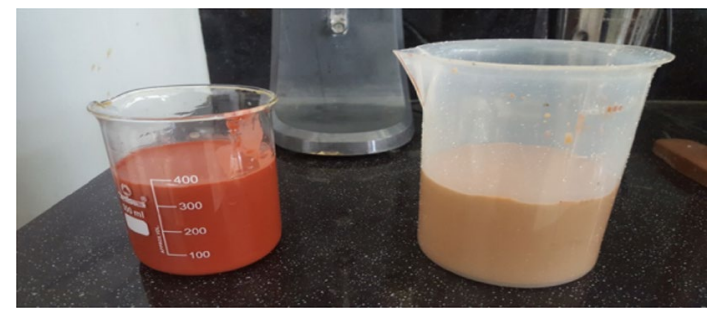

Fig. 24 Optimized CMC-bentonite mud (left), optimized PHPA-bentonite mud (right)

\section{Variation of properties with time}

Nevertheless, the data obtained from these small concentration of additives used can be utilized as it has been found that the yield point and gel strength decrease with higher concentration of $\mathrm{KCl}$ and $\mathrm{NaCl}$ as depicted by the circled area in the graphs. So, when tested the muds with variation of time, it can be seen that the swelling reduction has occurred in the reference PHPA mud with increasing amount of $\mathrm{KCl}$ and $\mathrm{NaCl}$ amount. This concludes that $\mathrm{NaCl}$ and $\mathrm{KCl}$ in small concentrations can still become swelling inhibitors even though the effects of the rheological and filtration properties are still inconclusive. (Talukdar and Gogoi 2015) It is still recommended to test the PHPA reference mud with higher concentration of additives to make further explanations.

\section{Swelling effect determination: theoretical}

Optimized CMC-bentonite and optimized PHPA-bentonite muds were made by adding a certain combination of additives into the respective reference muds. From the above experimental analyses and results, $3 \mathrm{~g}$ of $\mathrm{KCl}$ and $3 \mathrm{~g}$ of Haematite are considered optimum to be added into the CMC-bentonite mud. This combination was chosen because $\mathrm{KCl}$ looks to prevent the swelling effect even more as compared to $\mathrm{NaCl}$. Haematite was also added to slightly reduce the decrease in rheological properties. Furthermore, $3 \mathrm{~g}$ of KCl and $1 \mathrm{~g}$ of Haematite are considered optimum to be added into the PHPA-bentonite mud. Addition of $\mathrm{KCl}$

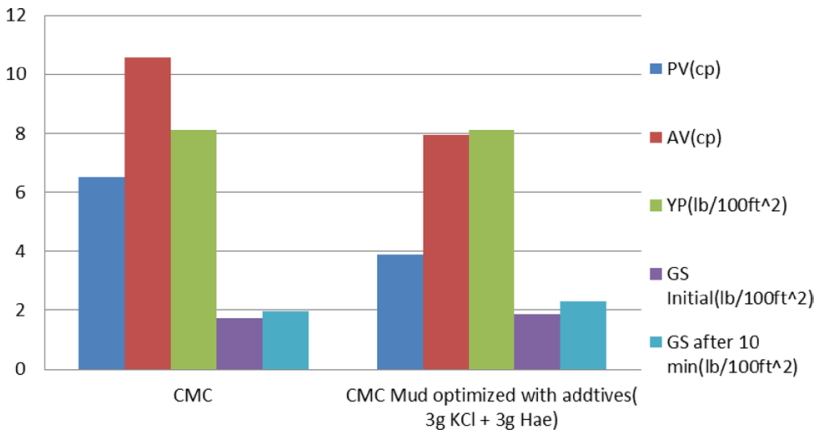

Fig. 25 Rheological properties of non-optimized vs optimized CMCbentonite mud

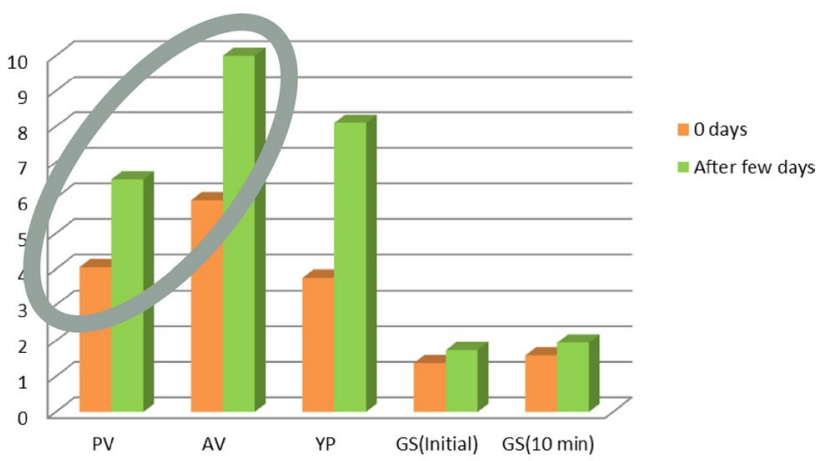

Rheological Properties of Normal CMC -Bentonite Mud

Fig. 26 Rheological properties of non-optimized CMC-bentonite mud in accordance with time

and $\mathrm{NaCl}$ together in a drilling fluid, however, does not prevent swelling as much as adding each of them on their own (Talukdar and Gogoi 2015). So, instead of $\mathrm{NaCl}, \mathrm{KCl}$ is added along with haematite in small quantity since the filtrate loss and mud cake thickness seem to be reduced.

\section{Difference between non-optimized and optimized CMC-bentonite muds}

The difference between non-optimized and optimized CMC-bentonite muds is shown in Table 3 and Figs. 25, 26 and 27. The data suggest that the optimized CMC-bentonite

Table 3 Density, viscosity and filtration properties of non-optimized vs optimized CMC-bentonite mud

\begin{tabular}{|c|c|c|c|c|c|c|c|}
\hline \multirow[t]{2}{*}{ Mud sample } & \multicolumn{2}{|l|}{ Mud balance } & \multirow[t]{2}{*}{$\begin{array}{l}\text { Marsh funnel } \\
\text { (time taken) }\end{array}$} & \multicolumn{2}{|c|}{$\begin{array}{l}\text { Dependant on density and Marsh fun- } \\
\text { nel time }\end{array}$} & \multirow{2}{*}{$\begin{array}{l}\text { Filtrate loss (ml) } \\
\text { After } 30 \mathrm{~min}\end{array}$} & \multirow{2}{*}{$\begin{array}{l}\text { Mud cake } \\
\text { thickness } \\
(\mathrm{mm})\end{array}$} \\
\hline & Specific gravity & Density (ppg) & & Effective viscosity & Apparent viscosity & & \\
\hline $\mathrm{CMC}$ & 1.070 & 8.90 & 44.26 & 172.18 & 145.36 & 24.15 & 1.1 \\
\hline $\begin{array}{l}\mathrm{CMC} \text { mud optimized } \\
\text { with additives }(3 \mathrm{~g} \\
\mathrm{KCl}+3 \mathrm{~g} \mathrm{Hae})\end{array}$ & 1.073 & 8.94 & 39.24 & 126.74 & 100.04 & 25.3 & 1.1 \\
\hline
\end{tabular}




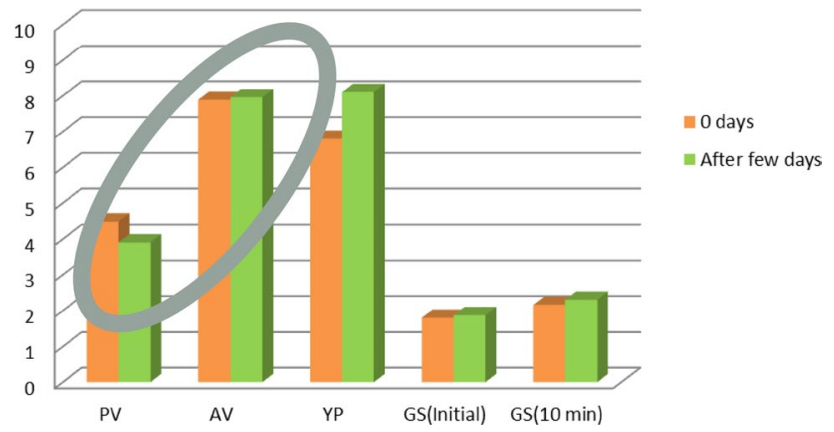

Fig. 27 Rheological properties of optimized CMC-bentonite mud in accordance with time

mud increased the density and specific gravity very slightly, but the apparent viscosity reduced qualitatively. The filtrate loss, on the other hand, with this combination additive ( $3 \mathrm{~g}$ $\mathrm{KCl}$ and $3 \mathrm{~g}$ haematite) to the drilling mud has increased the filtrate loss only by $1.15 \mathrm{ml}$, and the mud cake thickness remains almost same.

The data for optimized CMC-bentonite mud circled area in Fig. 27 indicate that the plastic and apparent viscosity readings have decreased due to the effect of the additives. This is because of the potassium ion moving into the lattice of the clay molecules and breaking the inner bonds of the muds itself; the viscosity is bound to decrease. As seen in Fig. 25, it is shown that the addition of these additives also reduces the rheological properties of the mud. And also the swelling of the optimized mud is much lower than that of the non-optimized CMC-bentonite reference mud. This means that the optimized CMC-bentonite mud is effective and is theoretically of use when drilling in formations that swell.

\section{Difference between non-optimized and optimized PHPA-bentonite muds}

As for the optimized PHPA mud, the density and specific gravity increase quite a bit due to the increased concentration of solids in the mud as shown in Table 4.

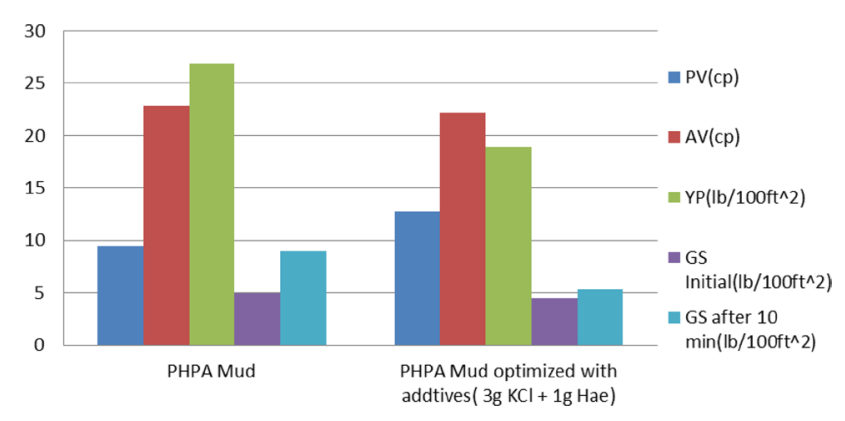

Fig. 28 Rheological properties of non-optimized vs optimized PHPA-bentonite mud

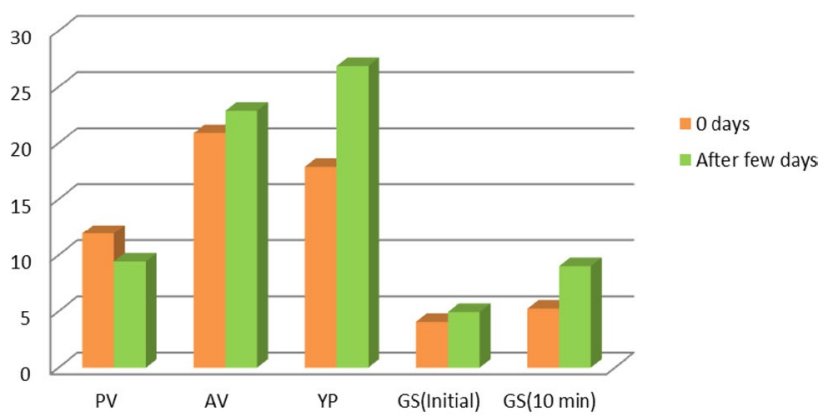

Rheological Properties of Normal CMC -Bentonite Mud

Fig. 29 Rheological properties of non-optimized PHPA-bentonite mud in accordance with time

Furthermore, its apparent viscosity decreased a lot. The filtrate loss and mud cake thickness, on the other hand, have increased slightly which is due to the breakdown of the fluid caused by the $\mathrm{KCl}$ addition.

When comparing the rheological properties as shown in Figs. 28, 29 and 30, the optimized PHPA mud exhibited higher plastic viscosity value due to the increase in solid concentration but show decrease in yield point and gel strength. And as expected, swelling has also been reduced in the optimized PHPA-bentonite mud theoretically.

Table 4 Density, viscosity and filtration properties of non-optimized vs optimized PHPA-bentonite mud

\begin{tabular}{|c|c|c|c|c|c|c|c|}
\hline \multirow[t]{2}{*}{ Mud Sample } & \multicolumn{2}{|l|}{ Mud balance } & \multirow[t]{2}{*}{$\begin{array}{l}\text { Marsh funnel } \\
\text { (time taken) }\end{array}$} & \multicolumn{2}{|c|}{$\begin{array}{l}\text { Dependant on density and Marsh fun- } \\
\text { nel time }\end{array}$} & \multirow{2}{*}{$\begin{array}{l}\text { Filtrate loss (ml) } \\
\text { After } 30 \mathrm{~min}\end{array}$} & \multirow{2}{*}{$\begin{array}{l}\text { Mud cake } \\
\text { thickness } \\
(\mathrm{mm})\end{array}$} \\
\hline & Specific gravity & Density (ppg) & & Effective viscosity & Apparent viscosity & & \\
\hline CMC & 1.045 & 8.75 & 101.92 & 673.08 & 646.83 & 14 & 1.2 \\
\hline $\begin{array}{l}\text { CMC mud optimized } \\
\text { with additives ( } 3 \mathrm{~g} \\
\mathrm{KCl}+3 \mathrm{~g} \mathrm{Hae})\end{array}$ & 1.060 & 8.89 & 72.0 & 417.83 & 391.16 & 15.07 & 1.6 \\
\hline
\end{tabular}




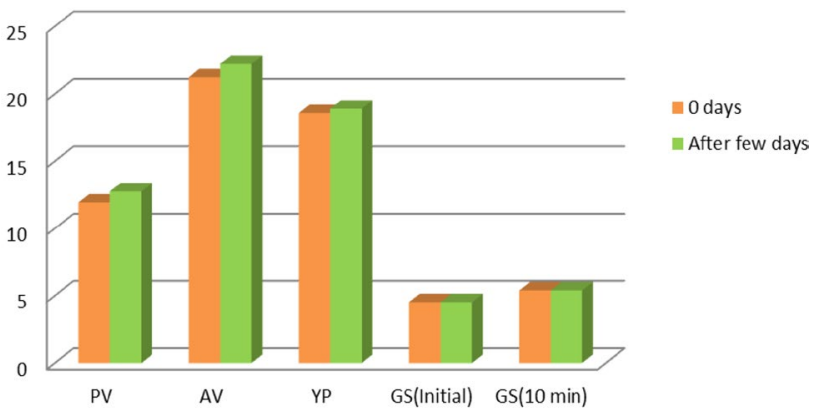

Rheological Properties of Normal CMC -Bentonite Mud

Fig. 30 Figure 83: rheological properties of optimized PHPA-bentonite mud in accordance with time

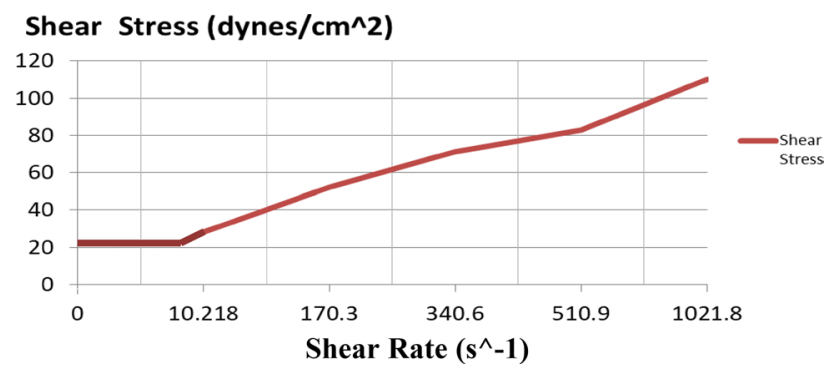

Fig. 31 Shear stress vs shear rate of optimized CMC-bentonite mud

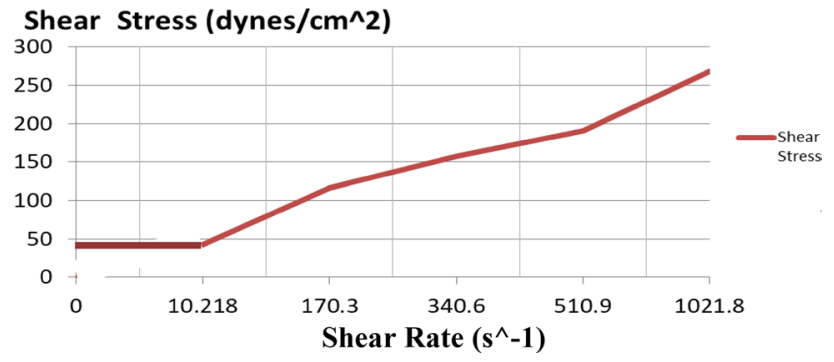

Fig. 32 Shear stress vs shear rate of optimized PHPA-bentonite mud

\section{Model of optimized CMC-bentonite and PHPA-bentonite fluids}

Both the optimized CMC and PHPA muds exhibited behaviours of a Herschel-Bulkley fluid as observed in Figs. 31 and 32 .

Using the power law model, the $n$ value was calculated for both muds and they are both less than 1 which proves that both muds are in fact Herschel-Bulkley in nature with yield stress points of more than zero. The shear stress graph achieves linearity when higher rates of rotation are used. The yield points of the muds are more than 0 as more stress is required to move the fluid. It can also be noticed from the graphs that the optimized PHPA mud has a very much higher shear stress scale

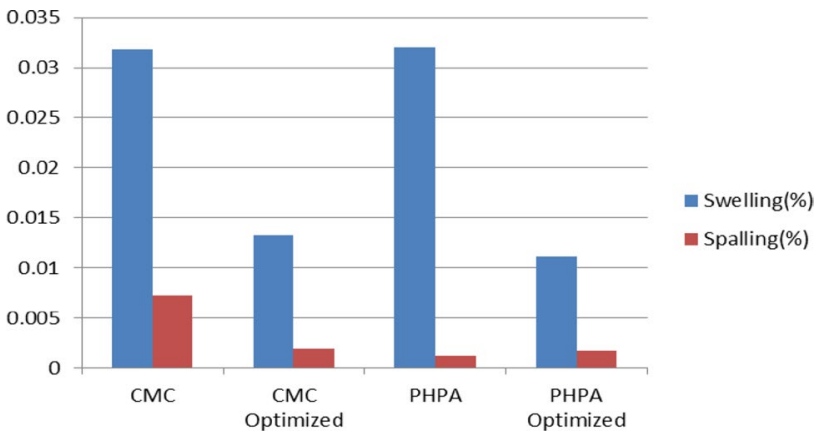

Fig. 33 Swelling/spalling of non-optimized vs optimized CMC-bentonite and PHPA-bentonite muds

compared to the shear stress scale of optimized CMC mud. This proves that more stress is required to shear through PHPA muds compared to CMC muds. In general, CMC salt acted better as a filtrate loss-reducing agent, while PHPA polymer gave better viscosity and shear stress values for their respective additions into the base drilling mud (Iscan and Kok 2007).

\section{Swelling effect determination: real-life application}

The data in Fig. 33 show that what was theoretically proven indeed produced the same results in the static immersion test.

The swelling effect of the shale rock has been reduced significantly for both optimized drilling muds as compared to the non-optimized muds. On the other hand, the spalling effect which means the formation of flakes on the rock surface remains almost similar.

\section{Conclusion}

Bentonite drilling fluid was tested with carboxymethyl cellulose, sodium salt, PHPA polymer and polyacrylamide, and it has been found that their addition led to the improvement in the rheological properties, creating higher viscosities and reducing the fluid loss content plus mud cake thickness. Furthermore, the modified CMC and PHPA polymer drilling fluids were then investigated with $\mathrm{NaCl}, \mathrm{KCl}$ and haematite mineral. $\mathrm{KCl}$ and $\mathrm{NaCl}$ acted as great swelling inhibitors for drilling muds, while haematite just slightly increased the rheological properties on CMC-bentonite mud and did not have much effect on the PHPA-bentonite mud. Potassium and sodium ions from $\mathrm{KCl}$ and $\mathrm{NaCl}$ break the bonds of clay molecules and enter their lattice preventing water ions from doing so. Swelling in shale formations can be greatly reduced with the 
addition of $\mathrm{KCL}$ and $\mathrm{NaCl}$ in both $\mathrm{CMC}$-bentonite and PHPA-bentonite mud systems. From this research, $\mathrm{KCl}$ is found to be the better inhibitor compared to $\mathrm{NaCl}$ since the potassium ions are more tightly held as compared to that of sodium ions. However, $\mathrm{NaCl}$ is the next best option to minimize swelling and is used also to formulate saturated saltwater drilling muds to drill salt domes.

Open Access This article is distributed under the terms of the Creative Commons Attribution 4.0 International License (http://creativeco mmons.org/licenses/by/4.0/), which permits unrestricted use, distribution, and reproduction in any medium, provided you give appropriate credit to the original author(s) and the source, provide a link to the Creative Commons license, and indicate if changes were made.

\section{References}

Almahdawi FH, Al-Yaseri AZ, Jasim N (2014) Apparent viscosity direct from marsh funnel test. Iraqi J Chem Pet Eng 15(1):51-57

Awele N (2014) Investigation of additives on drilling mud performance with "TØnder Geothermal Drilling" as a case study (unpublished master's thesis). Chemical Engineering Department, Aalborg University Esbjerg, Esbjerg

Borthakur A, Dutta Choudhury SR, Sengupta P, Rao KV, Nihalani MC (1997) Synthesis and evaluation of partially hydrolysed polyacrylamide (PHPA) as viscosifier in water based drilling fluids. Indian J Chem Technol 4:83-88
Carboxymethylcellulose. (n.d.). Retrieved from http://www.irochemica 1.com/product/MudDrilling/CMC.html

Iscan AG, Kok MV (2007) Effects of polymers and CMC concentration on rheological and fluid loss parameters of water-based drilling fluids. Energy Sour Part A Recovery Util Environ Effects 29(10):939-949

Kanna AP, Savi S, Khan M (2017) Determination of effect bentonite and additives on drilling fluids. Int Refereed J Eng Sci (IRJES) 6(3):22-28

Lam C, Jefferis SA (2014) Interpretation of viscometer test results for polymer support fluids. Tunn Undergr Constr. https://doi. org/10.1061/9780784413449.043

Limanowski J (2014) Effect of storage of diluted carboxymethylcellulose on rheological properties. Pol J Nat Sci 29(4):393-403

Polyacrylamide (PAM) (nd) Retrieved from http://www.irochemica 1.com/product/Mud-Drilling/PAM.html

Sharma H (2016) Study of geochemical interactions during chemical EOR processes (nd). Ph.D. thesis, Indian Institute of Technology Kanpur

Talukdar P, Gogoi SB (2015) Optimization of the composition of KCl and $\mathrm{KClNaCl}$ as a clay/shale stabilizing component in the NDDF for Upper Assam Basin. Int J Res Eng Appl Sci 5(12):16-38

Publisher's Note Springer Nature remains neutral with regard to jurisdictional claims in published maps and institutional affiliations. 